\title{
Immunotherapy Using IFN-Gamma for Cefaclor Allergy: Case Reports
}

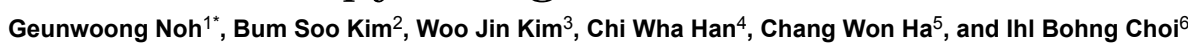

${ }^{1}$ Department of Allergy, Allergy and Clinical Immunology Center, Cheju Halla General Hospital, Seoul, Korea

${ }^{2}$ Department of Orthopedic Surgery' Cheju Halla General Hospital, Seoul, Korea

${ }^{3}$ Department of Laboratory Medicine, Cheju Halla General Hospital, Seoul, Korea

${ }^{4}$ Department of Hemato-Oncology, Cheju Halla General Hospital, Seoul, Korea

${ }^{5}$ Department of Pathology, Cheju Halla General Hospital, Seoul, Korea

${ }^{6}$ Department of Radiation Oncology, Cheju Halla General Hospital, Seoul, Korea

"Corresponding author: Geunwoong Noh, Department of Allergy, Allergy and Clinical Immunology Center, 65, Jeju-si Jeju Cheju Halla General Hospital, Doreongno Special Self-Governing Province, Seoul, Korea, Tel: +82-64-740-5064; E-mail: admyth@naver.com

Received date: February 26, 2018; Accepted date: March 6, 2018; Published date: March 13, 2018

Copyright: (c) 2018 Noh G, et al. This is an open-access article distributed under the terms of the Creative Commons Attribution License, which permits unrestricted use, distribution, and reproduction in any medium, provided the original author and source are credited.

\begin{abstract}
Cefaclor is prescribed worldwide and is one of the most frequently prescribed oral antibiotics. Several allergic reactions to cefaclor were reported. Desensitization for cefaclor allergy has been attempted and not all desensitization of cefaclor has been successful. IFN-gamma has been used for the tolerance induction for food allergies of both IgE-mediated and non-IgE mediated type. IFN-gamma was reported to have tolerogenic effects for allergen-specific allergies. Recently, IFN-gamma was introduced for desensitization for aspirin in acute myocardial syndrome. In this case report, two cases of patients who had anaphylactic allergies to cefaclor and treated successfully by desensitization using IFN-gamma were reported.
\end{abstract}

Keywords: Drug allergy; Desensitization; IFN-gamma

\section{Introduction}

Cefaclor is prescribed worldwide and is one of the most frequently prescribed oral antibiotics [1]. Allergic reactions to cephalosporins can be induced by the b-lactam ring structure common to all antibiotics from this family or by specific recognition to cephalosporin determinants [2].

The two main allergic responses are urticarial and anaphylaxis [3]. Many serum sickness type reactions to cefaclor have been reported $[4,5]$. Patients administered cefaclor had a higher frequency of serum sickness type reactions and urticaria than those prescribed amoxicillin [6]. Several anaphylactic reactions to cefaclor were reported for the first time [7].

Drug tolerance by desensitization has been known as a temporary state in which a patient with a known drug allergy will tolerate the culprit drug without an adverse reaction [8]. An induction of drug tolerance procedure temporarily modifies a patient's response to a drug, allowing safe treatment with it. Tolerance is maintained only as long as the patient continues to take the specific drug. Moreover, not all desensitization for drug allergy is successful.

Cephalosprin desensitization was well described in 2013 [9]. IFNgamma has been used for the tolerance induction for food allergy of both IgE-mediated and non-IgE mediated type [10]. IFN-gamma was reported to have tolerogenic effects for allergen-specific allergy [11]. Recently, IFN-gamma was introduced for desensitization for aspirin in acute myocardial syndrome [12].

In this case report, two cases of patients who had anaphylactic allergy for cefaclor and treated by desensitization using IFN-gamma were reported.

\section{Case Report}

\section{Case 1}

A 48 year-old female patient who complained about allergy to multiple drugs visited Allergy \& Clinical Immunology Center, Cheju Halla General Hospital. Patients want to get one safe antibiotics for the unexpected condition to use antibiotics. In the past histories, patient showed chilling, generalized myalgia, dancing body temperature and transient paralysis on whole body after using unidentified antibiotic after delivery 25 years ago as a first episode. The second and third episode is that patients felt chilling and tremors of whole body by intramuscular injection of gentamycin in the local clinic 2 years ago. The patient continued without antibiotic mediation due to the suspected multiple drug allergy syndromes in spite of conditions in which she should have received antibiotics due to surgery of urinary bladder in the local clinic. She had a history of transient paralysis of lower extremities after intramuscular injection of analgesics. She wanted to get one safe antibiotic for the future.

Her wounds by injury or surgery have not healed well. The erythema and eruption occurred frequently when she took unidentified foods. Also, urticarial occurred when she was in hazy air, exposed to grass, or went to the mountains. She also had white dermographism and was made severely ill by a flue vaccination. Under the diagnosis of suspected multiple drug allergies, a safe antibiotic was necessary for variable reasons and she also wanted to find a safe oral antibiotic to take. She was admitted and an oral drug challenge was performed for cefaclor.

Blood tests and skin prick tests were performed for general allergy laboratory analysis. In complete blood count with differential count, eosinophil fractions were $1.4 \%$ (normal range, 0-5. Initial serum eosinophil cationic protein level was high as $18.60 \mu \mathrm{g} / \mathrm{L}$ (normal range, 
0.0-14.9 $\mu \mathrm{g} / \mathrm{L}$ ). Serum total IgE levels were $30.1 \mathrm{KU} / \mathrm{L}$ (normal range, $350 \mathrm{KU} / \mathrm{L}>)$.

Specific IgE levels which were tested for 40 allergens by MAST (Green Cross ${ }^{\circ}$, Seoul Korea). Only two allergens (Cat (1.30 IU/ml, 2+) and Dog $(0.41 \mathrm{IU} / \mathrm{ml}, 1+))$ showed positive results and other allergens (Dermatophagoides pteryonyssinus, Dermatophagoides farinae, Egg white, Milk, Soybean, Shrimp, Peach, Mackerel, Crab, Rye, Cockroach, Cladosporium, Aspergillus, Alternaria, Birch/Alder, White oak, Short ragweed, Mugwork, Japanese hop, Hazelnut, Sweet Grass, Bermuda Grass, Cocksfoot, Timothy Grass, Reed, Ox-eye daisy, Penicillium, Sycamore, Sallow willow, Cottonwood East, Ash mix, Pine, Japanese Cedar, Acacia, Dandelion, Russian thistle, Goldenrod, and Pigweed) were negative.

Skin prick tests were performed and she is poly-sensitized for multiple variable allergens. Among 53 items, 25 allergens (Alternaria alternate (2+), Aspergillus fumigatus (2+), Penicilium Chrysogerium $(2+)$, Dermatophagoides pteronyssinus (2+), Dermatophagoides farina (3+), Dog (2+), Gray Alder (Silver Birch) (3+), Grass mix (3+), Mugwort (2+), Short Ragweed (2+), Black willow pollen (3+), Orchard $(1+)$, Bermuda grass $(2+)$, Timothy $(2+)$, Holm oak $(2+)$, Japanese cedar $(3+)$, Pork $(2+)$, Cod $(2+)$, Prawn $(2+)$, Almond $(2+)$, Peanut $(2+)$, Walnut $(2+)$, Peach $(2+)$, Black pepper $(3+)$, F acacia $(2+))$ showed positive results and remains (Aspergillus niger, Candida albicans, Clasdosporium, German cockroach, Cat, English plantain, English Rye grass, Cotton flock, Milk, Egg, Chicken, Beef, Oyster, Salmon, Mackerel, Tuna, Bean, Carrot, Cabbage, Maize, Tomato, Spinach, Wheat, Rabbit, Kapok, Hop, Pine and Poplar) were negative.

Specific IgE (0.10 KU/L, normal range $0.00-0.35 \mathrm{KU} / \mathrm{L})$, skin prick test and intradermal test for cefaclor were negative.

Oral drug challenge (ODC) was started with dose of cefaclor $5 \mathrm{mg}$ At the $10 \mathrm{mg}$ dose of cefaclor, patient showed vomiting, hypertension (systolic 168/diastolic 110, usually normal) and itching after she took $10 \mathrm{mg}$ of cefaclor. The next day, $10 \mathrm{mg}$ of cefaclor was given again and patient showed more severe symptoms and signs with choking sensations, dyspnea, skin rash, generalized itching of whole body, coughing, and hand tremors (Figure 1). The diagnosis of IgE-mediated allergy for cefaclor was made and anaphylactic shock was expected with higher dosage. The minimal provocation dose is $10 \mathrm{mg}$. Patient also met impediment at the $10 \mathrm{mg}$ dose of cefaclor by confirmation of repetitive challenge.

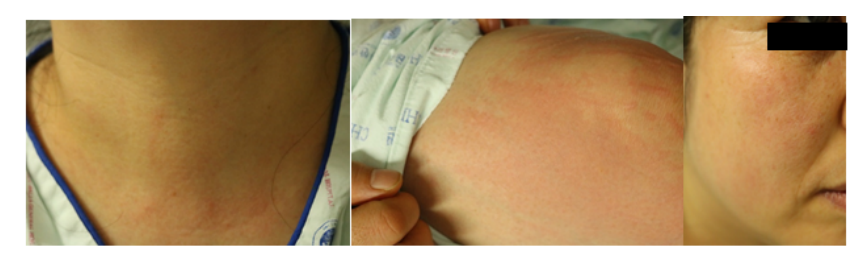

Figure 1: Skin manifestation of allergic responses to cefaclor with minimal provocation dose (cefaclor $10 \mathrm{mg}$ ) in case 1 . Generalized itching, excoriation and skin rash were developed. Also, white dermographism was observed.

IFN-gamma (Intermax gamma, LG Chemistry ${ }^{\oplus}$, Seoul, Korea) was introduced to overcome the impediment. It was administered at a dose of 2,000,000 Unit $(50 \mu \mathrm{g})$ subcutaneously on the arm $15 \mathrm{~min}$ before the challenge of impediment dose. Acetaminophen $650 \mathrm{mg}$ was prescribed 15 min before IFN-gamma injection to avoid untoward side reactions of IFN-gamma including headache, myalgia, abdominal pain. IFNgamma was administered early in the morning.

Patient did not respond to $10 \mathrm{mg}$ of cefaclor with pretreatment with IFN-gamma as an adjuvant immunomodulatory drug. Thereafter the patient no longer showed any symptoms or signs with the progression of desensitization without IFN-gamma according to the protocol. Thereafter, the patient finished desensitization and she was taking 250 $\mathrm{mg}$ of cefaclor every day for 3 months without any adverse reactions.

\section{Case 2}

A 43 year-old female patient visited Allergy \& Clinical Immunology Center, Cheju Halla General Hospital because of a drug allergy. The patient had history of emergency treatment due to severe allergic reaction after taking oral medications for an upper respiration infection 7 years ago. Patient showed vomiting, diarrhea, abdominal pain. Blood pressure decreased and she experience transient loss of vision and it is suspected to be loss of consciousness. Patient took oral medication of cefaclor, acetaminophen and streptokinase just before the development of anaphylaxis. She was diagnosed with an allergy to aspirin but not to acetaminophen. An allergy to cefaclor was suspected

Thereafter, she visited the emergency room three times more; 20 months ago due to severe angioedema including face, 16 months ago due to anaphylaxis and 1 months ago due to anaphylaxis, after intake of medications for upper respiratory infection including cefaclor. Patient was admitted to confirm drug allergy for cefaclor by oral drug challenge test.

Blood tests and skin prick tests were performed for general allergy laboratory analysis. In complete blood count with differential count, eosinophil fractions were $4.7 \%$ (normal range, 0-5\%). Serum eosinophil cationic protein level was $2 \mathrm{mg} / \mathrm{L}>$ (normal range, 0.0-14.9 $\mathrm{g} / \mathrm{L}$ ). Serum total IgE levels were $133.0 \mathrm{KU} / \mathrm{L}$ (normal range, $350 \mathrm{KU} /$ $\mathrm{L}>$ ).

Specific IgE levels which were tested for 40 allergens by MAST (Green Cross ${ }^{\oplus}$, Seoul Korea). Cat $(2.00 \mathrm{IU} / \mathrm{ml}, 3+)$, Rye $(4.80 \mathrm{IU} / \mathrm{ml}$, $3+$ ) Sweet Grass (4.31 IU/ml, 3+), Bermuda Grass (1+), Cocksfoot $(2+)$, Timothy Grass $(2+)$, Reed $(1+)$ were positive and other allergens (Dermatophagoides pteryonyssinus), Dermatophagoides farinae, Dog, Egg white, Milk, Soybean, Shrimp, Crab, Peach, Mackerel, Cockroach, Cladosporium, Aspergillus, Alternaria, Birch/Alder, White oak, Short ragweed, Mugwork, Japanese hop, Hazelnut, Penicillium, Sycamore, Sallow willow, Cottonwood East, Ash mix, Pine, Japanese Cedar, Acacia, Dandelion, Russian thistle, Goldenrod, Ox-eye daisy and Pigweed) were negative.

Skin prick test was conducted for 53 allergens. 11 items (Dermatophagoides pteronyssinus (3+), Dog (2+), Cat (3+), Gray Alder (Silver Birch) (3+), Grass mix (3+), Mugwort (2+), Orchard $(6+)$, Bermuda grass (2+), Timothy (3+), English Rye grass (3+), Japanese cedar $(2+)$ ) were positive and remains (Alternaria alternate, Aspergillus fumigatus, Aspergillus niger, Candida albicans, Clasdosporium, Penicilium Chrysogerium, German cockroach, Dermatophagoides pteronyssinus, Dermatophagoides farina, Short Ragweed, Black willow pollen, English plantain, Holm oak, Cotton flock, Milk, Egg, Chicken, Beef, Pork, Cod, Oyster, Salmon, Prawn, Mackerel, Tuna, Almond, Peanut, Bean, Carrot, Cabbage, Walnut, Maize, Peach, Tomato, Black pepper, Spinach, Wheat, Rabbit, Kapok, Hop, F acacia, Pine and Poplar) were negative. 
Page 3 of 4

Cefaclor was challenged according to the protocol. The initial dose was $5 \mathrm{mg}$. Then the patient showed respiratory difficulty with dyspnea with administration of $5 \mathrm{mg}$ of cefaclor. The patient was re-challenged with cefaclor $5 \mathrm{mg}$ after $1 \mathrm{hr}$, and the patient suffered from severe chest tightness, respiratory difficulty with nausea and vomiting, skin rash, generalized edema and periorbital angioedema with facial edema (Figure 2). The challenge test was stopped at the dose of cefaclor $5 \mathrm{mg}$ and the anaphylactic drug allergy for cefaclor was diagnosed.

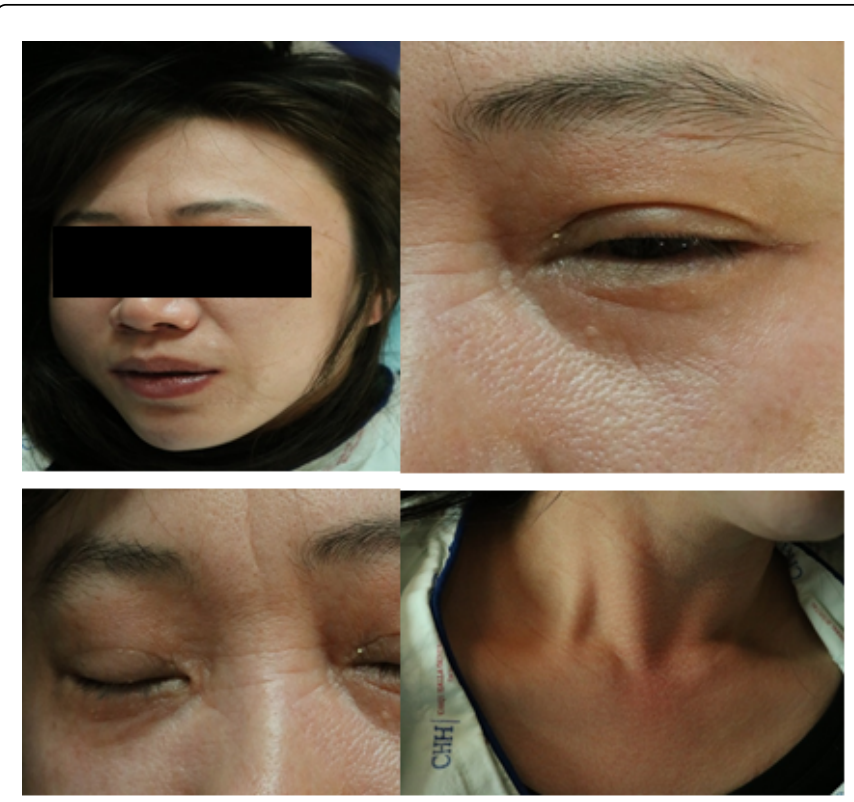

Figure 2: Allergic responses to cefaclor with minimal provocation dose (cefaclor $5 \mathrm{mg}$ ) in case 2. Angioedema on periorbital area and skin rashes on face and neck were observed.

The patient wanted desensitization and IFN-gamma was introduced to overcome impediment at the dose of $5 \mathrm{mg}$. IFN-gamma was given $2,000,000 \mathrm{IU}(50 \mathrm{mg})$ subcutaneously $15 \mathrm{~min}$ before the second challenge of the minimal provocation dose, cefaclor $5 \mathrm{mg}$ as an impediment dose. The patient did not showed any allergic symptoms or signs after giving cefaclor with IFN-gamma. After that, the patient did not show any symptoms or signs with increasing doses of cefaclor and desensitization was successfully finished. In hospital day 2 , she was discharged and oral cefaclor $250 \mathrm{mg}$ was given daily without any symptoms and signs for more than 3 months.

\section{Discussion}

Desensitization for cefaclor is successfully achieved using IFNgamma as an immunomodulatory adjuvant even when the physician met the impediment in which allergy provocation occurred by cefaclor challenge.

First of all, practical protocols for patients requiring the prompt administration of cefaclor were required [1]. Moreover, a limitation of desensitization is that in patients who failed the pre-existing desensitization protocol, a new attempt to desensitize was necessary. The issues of desensitization when the patient met the impediment during the desensitization with conventional previous concepts without IFN-gamma were the time consuming and success of desensitization. IFN-gamma has tolerogenic effects for allergens
$[11,13,14]$ and induction of allergen-specific regulatory B cells was reported partially responsible for tolerogenic effects of IFN-gamma $[15,16]$

Recently, desensitization for patients who had an aspirin allergy with acute myocardial syndrome was successfully achieved. In this report, the impediment during desensitization of cefaclor was easily overcome using IFN-gamma only once in this case report in both two cases. From our results, IFN-gamma may be also useful for the desensitization for the allergy to many other drugs as a new concept and a new therapeutic protocol.

In this case study, the dosage range of allergy provocation in cefaclor allergy is estimated. Basically, the approximate dosage unit was $\mathrm{mg}$ scale, one was $5 \mathrm{mg}$ and other was $10 \mathrm{mg}$. The dosage range is very important to make the more effective protocol for oral drug challenge. From the results of these cases, the protocol of challenge test for cefaclor allergy may be started from $0.5 \mathrm{mg} 1 \mathrm{mg}$.

IFN-gamma was used in every challenges of allergenic food with increasing dose during tolerance induction [14]. However, in desensitization of drug allergy, IFN-gamma was used just to overcome the impediment in which patients showed allergic reactions at a certain dose; $10 \mathrm{mg}$ (case 1) and $5 \mathrm{mg}$ (case 2) (Table 1). It is not necessary to use IFN-gamma in every challenges of allergenic drug with increasing dose during desensitization.

\begin{tabular}{|l|l|l|l|l|l|}
\hline Sequence & $\begin{array}{l}\text { Dose } \\
\text { (mg) }\end{array}$ & Case 1 & \multicolumn{2}{l|}{ Case 2 } \\
\hline & $\begin{array}{l}\text { Impediment \& } \\
\text { IFN-gamma }\end{array}$ & Cycle & $\begin{array}{l}\text { Impediment \& } \\
\text { IFN-gamma }\end{array}$ & Cycle \\
\hline 1 & 2.5 & & & & \\
\hline 2 & 5 & & & O & 1 \\
\hline 3 & 7.5 & & & & \\
\hline 4 & 10 & 0 & 1 & & \\
\hline 5 & 15 & & & & \\
\hline 6 & 20 & & & & \\
\hline 7 & 25 & & & & \\
\hline 8 & 50 & & & & \\
\hline 9 & 100 & & & & \\
\hline 10 & 150 & & & & \\
\hline 11 & 200 & & & & \\
\hline 12 & & & & & \\
\hline
\end{tabular}

Table 1: CHH standard protocol for cefaclor desensitization and IFNgamma use. IFN-gamma was used only once just to overcome impediment. Every repetition at the same dose using IFN-gamma was counted as a cycle. When patient met the impediment at a certain dose, IFN-gamma was administrated before the repeated challenge of impediment dose. The number of repetitive treatment using IFNgamma was the number of cycle. However, in this report, two patients overcome the impediment just by 1 cycle of IFN-gamma use.

Conclusively, IFN-gamma is very useful to achieve tolerance for allergenic drug by overcome the impediment with allergy provocation 
by challenging a certain dose during the desensitization. Dose unit of minimal allergy provocation of cefaclor allergy was $\mathrm{mg}(5 \mathrm{mg}$ and 10 $\mathrm{mg}$ ). IFN-gamma was used for the tolerance induction for anaphylactic food allergy. Differently from that in food allergy, IFN-gamma was used in every challenge of allergenic food during tolerance induction whereas IFN-gamma was used only to overcome the impediment during the desensitization for allergenic drug and only allergenic drug was challenged for remains in drug allergy.

\section{References}

1. Col NF, O'Connor RW (1987) Estimating worldwide current antibiotic usage Report of task force 1. Rev Infect Dis 3: 232-243.

2. Ministry of Health and Welfare (1987) Cefaclor-induced shock. Information Adverse Drug React No 84: 1-2.

3. Levine LR (1985) Quantitative comparison of adverse reactions to cefaclor vs amoxycillin in a surveillance study. Pediatr Infect Dis 4: 358-361.

4. Perez-Inestrosa E, Suau R, Montañez MI, Rodriguez R, Mayorga C, et al. (2005) Cephalosporin Chemical Reactivity and its immunological implications. Curr Opin Allergy Clin Immunol 5: 323-330.

5. Yoo HS, Kim SH, Kwon HS, Kim TB, Nam YH, et al. (2014) Immunologic evaluation of immediate hypersensitivity to cefaclor. Yonsei Med J 55: 1473-1483.

6. Solensky R, Khan DA, Bernstein IL, Bloomberg GR, Castells MC (1980) Cefaclor. a cluster of adverse reactions. N Engl J Med 303: 1003.

7. Swedish Adverse Drug Reactions Advisory Committee (1986) Hypersensitivity reactions to cefaclor. Bull SADRAC 47: 2-3.

8. Solensky R, Khan DA, Bernstein IL, Bloomberg GR, Castells MC, et al (2010) Drug allergy: an updated practice parameter. Ann Allergy Asthma Immunol 105: 273e1-e78.
9. Dickson SD, Salazar KC (2013) Salazar Diagnosis and Management of Immediate Hypersensitivity Reactions to Cephalosporins. Clinic Rev Allerg Immunol 45: 131-142.

10. Lee JH, Noh G, Noh J, Lee S, Choi WS, et al. (2010) Clinical characteristics of oral tolerance induction of IgE-mediated and non-IgEmediated food allergy using interferon gamma. Allergy Asthma Proc 31: e39-e47.

11. Noh G, Lee SS (2003) Effects of IFN-gamma on milk-specific oral tolerance induction for milk allergy in atopic dermatitis: Food-specific oral tolerance induction using IFN-gamma as adjuvant. In: Marone G Clinical immunology and allergy in medicine. Naples. JGC 475-496.

12. Noh G, Kang SH, Lee K, Kim WJ, Han CW, et al. (2017) Rush Immunotherapy Using IFN-Gamma for Aspirin in Acute Coronary Syndrome: Case Report. J Allergy Ther 8: 269-273.

13. Noh G, Lee KY (2000) Pilot study of IFN-gamma-induced specific hyposensitization for house dust mites in atopic dermatitis: IFN-gammainduced immune deviation as a new therapeutic concept for atopic dermatitis. Cytokine 12: 472-476.

14. Noh G, Lee SS (2009) A pilot studies of interferon-gamma-induced specific oral tolerance induction (ISOTI) for immunoglobulin Emediated anaphylactic food allergy. J Interferon Cytokine Res 29: 667-675.

15. Noh J, Noh G, Lee SJ, Lee JH, Kim A, et al. (2012) Tolerogenic effects of interferon-gamma with induction of allergen-specific interleukin-10producing regulatory $\mathrm{B}$ cell $(\mathrm{Brl})$ changes in non-IgE-mediated food allergy. Cell Immunol 273: 140-149.

16. Lee SJ, Noh G, Lee JH (2013) In Vitro Induction of Allergen-Specific Interleukin-10-Producing Regulatory B Cell Responses by Interferon- $\gamma$ in Non-Immunoglobulin E-Mediated Milk Allergy. Allergy Asthma Immunol Res 5: 48-54. 